Review

\title{
Supplementary cementitious materials origin from agricultural wastes - A review
}

\author{
Evi Aprianti ${ }^{\mathrm{a}, *}$, Payam Shafigh $^{\mathrm{b}}$, Syamsul Bahri ${ }^{\mathrm{b}}$, Javad Nodeh Farahani ${ }^{\mathrm{b}}$
}

${ }^{a}$ Department of Building Surveying, Faculty of Built Environment, University of Malaya, Malaysia

${ }^{\mathrm{b}}$ Department of Civil Engineering, Faculty of Engineering, University of Malaya, Malaysia

H I G H L I G H T S

- Potential uses of agricultural wastes as cementitious material were reviewed.

- Ashes from agricultural wastes have high silica content.

- The use of RHA is limited due to the porosity nature of RHA particles.

- POFA has good potential to be used as cementitious material in cement based materials.

\section{A R T I C L E I N F O}

Article history:

Received 25 July 2014

Accepted 8 October 2014

Available online 9 November 2014

Keywords:

Supplementary cementitious material

Pozzolans

Concrete

Compressive strength

Agricultural waste
A B S T R A C T

Concrete is heavily used as a construction material in modern society. With the growth in urbanization and industrialization, the demand for concrete is increasing day by-days. Therefore, raw materials and natural resources are required in large quantities for concrete production worldwide. At the same time, a considerable quantity of agricultural waste and other types of solid material disposal are posing serious environmental issues. To minimize and reduce the negative impact of the concrete industry through the explosive usage of raw materials, the use of agricultural wastes as supplementary cementitious materials, the source of which are both reliable and suitable for alternative preventive solutions promotes the environmental sustainability of the industry. This paper reviews the possible use of agricultural wastes as a supplementary cementitious material in the production of concrete. It aims to exhibit the idea of utilizing these wastes by elaborating upon their engineering, physical and chemical properties. This provides a summary of the existing knowledge about the successful use of agricultural wastes such as rice husk ash, palm oil fuel ash, sugar cane bagasse ash, wood waste ash, bamboo leaf ash, and corn cob ash in the concrete industry.

2014 Elsevier Ltd. All rights reserved.

Contents

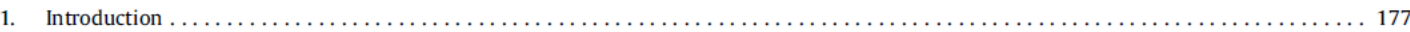

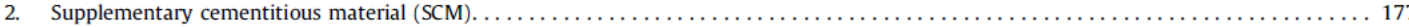

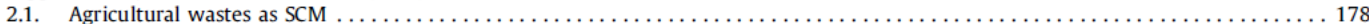

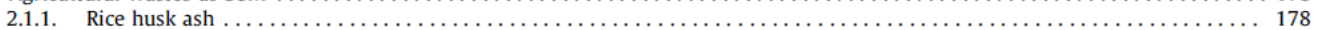

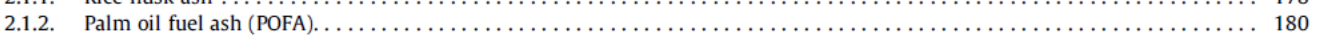

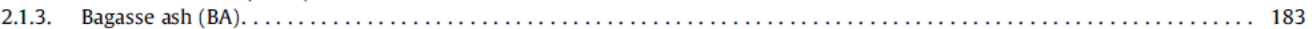

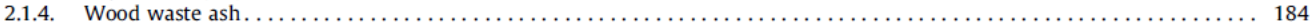

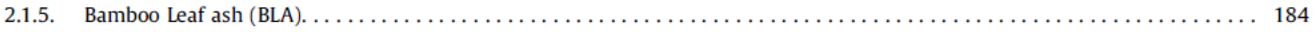

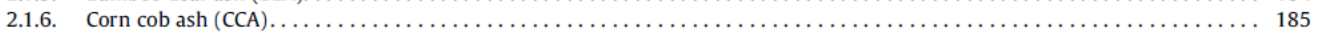

* Corresponding author. Tel.: +60 1114247118; fax: +60 379675713.

E-mail addresses: eviaprianti93@siswa.um.edu.my, eviaprianti93@yahoo.com (E. Aprianti).

http://dx.doi.org/10.1016/j.conbuildmat.2014.10.010

0950-0618/@ 2014 Elsevier Ltd. All rights reserved. 


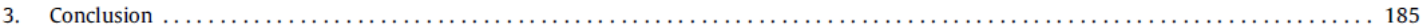

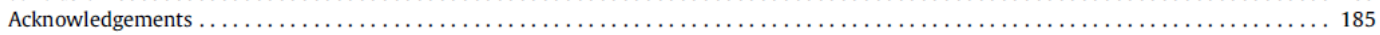

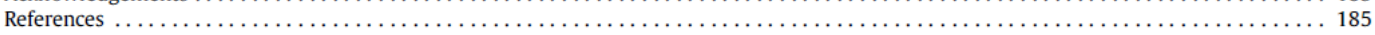

\section{Introduction}

Today, concrete has become the most commonly used building material in the construction industry. The other important characteristics of concrete, besides its strength, are its ability to be easily moulded into any form, it is an engineered material that can meet almost any desired specification, and it also adaptable, incombustible, affordable and easily obtained. The great advantage of concrete is its excellent mechanical and physical characteristics, if properly designed and manufactured. Currently, concrete is extensively used with more than 10 billion tons produced annually in modern industrial society [1]. It has been estimated that by 2050 , the rate of the world's population will grow substantially from 1.5 to 9 billion, and, thus, will cause an increase in the demand for energy, housing, food and clothing as well as for concrete, which is forecast to increase to approximately 18 billion tons annually by 2050 [2].

Unfortunately, a considerable quantity of concrete is being produced, the effect of which is contrary to its benefits. In the last 100 years, the concrete industry has had an enormous effect on the environmental appearances. In addition, $\mathrm{CO}_{2}$ emissions are caused during the manufacturing process with a large volume of raw materials required to produce the billions of tons of concrete worldwide each year. The cement industry alone is estimated to be responsible for about $7 \%$ of all the $\mathrm{CO}_{2}$ generated worldwide [3]. It has been found that every ton of Portland cement produced releases approximately one ton of $\mathrm{CO}_{2}$ into the atmosphere. In addition, during the production of cement and concrete, issues like carbon dioxide emissions, along with the use of energy and aggregate consumption in great amounts, the demolition waste of concrete, and filler requirements, contribute to the common environmental impact that concrete has making it a non-friendly that is unsuitable for sustainable development.

Several studies have focused on finding alternatives that can be used as replacement to cement, such as, the disposable and less valuable wastes from industry and agriculture, whose potential benefits can be realized through recycling, reuse and renewing programmes. Hence, researchers have been investigating the effectiveness, efficiency and availability of waste materials that are pozzolanic in nature as a cement replacement. The required materials should be a by-product from an-original source that is rich in silicon $(\mathrm{Si})$ and aluminium $(\mathrm{Al})$. The framework for utilizing industrial waste material for building applications has a successful history, which includes fly ash, slag, and silica fume. Consequently, land filled waste materials that are normally disposed of and land filled are now deemed to be valuable for enhancing the desired properties of concrete.

Previous studies showed that some agro-waste materials could be used as a cement replacement in cement based materials. The utilization of agricultural waste can provide the break-through needed to make the industry more environmentally friendly and sustainable. The purpose of this paper is to clearly describe and briefly introduce waste materials from agricultural commodities that have been well managed and successfully used as supplementary cementitious materials ( $\mathrm{SCM}$ ) for the manufacture of concrete. The relationships among concrete made using these types of waste materials, environmentally friendly concrete, and green building rating systems are also discussed. Mutual recognition of these materials, and their usage in concrete by both civil engineers and agricultural engineers, would pave the way for other potential uses of solid waste materials in the construction industry, as well as certain other industries. It will also lead to a more environmentally sustainable concrete industry.

\section{Supplementary cementitious material (SCM)}

A substantial quantity of waste materials are produced globally as by-products from different sectors, such as industrial, agricultural, and wastes from rural and urban society. These waste materials, if not deposited safely, it may be hazardous. The type and amount of sewage produced increases with the growth in population. These wastes remain in the environment for a longer duration since they are unused. The waste disposal crisis has arisen due to the formation of decomposed waste materials. The solution to this crisis lies in the recycling of wastes into useful products. Research into the innovative uses of waste materials is continuously advancing. Waste and by-product materials, such as fly ash, silica fume, ground granulated blast slag, rice husk ash, and palm oil fuel ash have been successfully used in concrete for decades [4-8]. The successful usage as a partial or whole replacement of Portland cement, contributes to the resolution of the landfill problem and reduction in the cost of building materials, provides a satisfactory solution to the environmental issues and problems associated with waste management, saves energy, and helps to protect the environment from pollution. Agricultural wastes, such as rice husk ash, wheat straw ash, and sugarcane bagasse ash, hazel nutshell ash which constitute pozzolanic materials can be used as a replacement for cement.

Today, supplementary cementing materials are widely used as pozzolanic materials (create extra strength by pozzolanic reaction) in high-strength concrete, reduce permeability and improve the durability of the concrete. Many types of pozzolans are used globaily, and are commonly used as an addition or replacement for Portland cement in concrete. It is well known that pozzolanic concrete contributes to the compressive strength in two ways: as the filler effect and the pozzolanic reaction. Thus, the pozzolanic material will reduce the demand or usage of cement at that time. A pozzolan comprises siliceous materials, and when combined with calcium hydroxide, exhibits cementitious properties depending on the constituents of the pozzolan. On the other hand, the "high early strength" concrete can be produced by the highly reactive silica in pozzolans. The basis of the pozzolanic reaction is a simple acid-based reaction between calcium hydroxide, also known as Portlandite $\left(\mathrm{Ca}(\mathrm{OH})_{2}\right)$ and silicic acid $\left(\mathrm{Si}(\mathrm{OH})_{4}\right)$. This reaction is represented as follows:

$$
\begin{aligned}
\mathrm{Ca}(\mathrm{OH})_{2}+\left(\mathrm{Si}(\mathrm{OH})_{4}\right) & \rightarrow \mathrm{Ca}_{2}++\mathrm{H}_{2} \mathrm{SiO}_{4}^{2-}+2 \mathrm{H}_{2} \mathrm{O} \\
& \rightarrow \mathrm{CaH}_{2} \mathrm{SiO}_{4} \cdot 2 \mathrm{H}_{2} \mathrm{O}
\end{aligned}
$$

And is the same as the abbreviated notation below:

$$
\mathrm{CH}+\mathrm{SH} \rightarrow \mathrm{CSH} \tilde{\mathrm{C}}-\mathrm{S}-\mathrm{H}
$$

As the density of CSH is lower than that of Portlandite and pure silica, a consequence of this reaction is a swelling of the reaction products. This reaction, which is also known as alkali-silica reaction may occur over time in concrete between the alkaline cement pore water and poorly-crystalline silica aggregates. 
Basically, concrete is a combination of cement, water, fine and coarse aggregate. As consequence of the greenhouse gas emissions (GHG), most concrete mixtures utilize supplementary cementitious materials (SCMs) either in blended cements or added separately in the mixer. The utilization of SCMs, such as rice husk ash, which is a by-product from agriculture, represents a viable solution to the partial cement substitution. Which is divided into natural and artificial materials. The usage of SCMs without the additional process causes a significant decrease in $\mathrm{CO}_{2}$ emissions per ton in the atmosphere. These materials are also referred to as mineral admixtures or pozzolans, and when used in concrete and combined with Portland cement form cementitious particles, however by themselves, they do not possess any cementitious compounds. They should meet the requirements of the established standards.

The structural advantage of SCMs is that they enable the producer to modify the mixture and calculate the proper design of the desired application. In addition, it can be used to improve the performance of concrete, either in fresh or hardened mixtures. In economic terms, using alternative waste materials can reduce the cost of construction while providing comparable performance. This cost includes the source and transportation of the alternative material, controlled combustion process, and savings through diversion, such as disposal management. Subsequently, the environmental benefits will decrease the sizeable needs and demand of Portland cement per unit volume of concrete as well as the impact on the enormous deflation range of GHG emissions.

\subsection{Agricultural wastes as SCM}

Nowadays, global environmental warming is considered to be the most important worldwide issue. Solid waste materials are found everywhere, such as in the urban and rural society, industry and agriculture. As agricultural wastes affect of the environment the use of these waste materials in construction will realize the many benefits previously mentioned. Research has determined that concrete that produced using agricultural wastes presents improved thermal properties [13,27,36-49], which can result in significant points being gained in the atmosphere and energy category of Leadership in Energy and Environmental Design (LEED) rating system. Moreover, due to the high cost constraints and limited availability of the main material in concrete, particularly in developing countries, agricultural wastes used as SCMs in concrete production can contribute to the environmental friendliness and economic effectiveness of structures worldwide.

\subsubsection{Rice husk ash}

Rice husk is a natural sheath that forms around rice grains during their growth. It is widely available in rice-producing countries, and considered to be an agricultural solid waste material. Rice husk has no commercial value when removed during the refining process. The rice milling industry is one of the most important sectors in some countries, such as China, India, Indonesia, Malaysia and Bangladesh, and worldwide by the end of 2013, the rice husk harvest produced approximately 742 million metric tons of rice paddies annually [9]. Of this, more than $20 \%$ comprised the husk India produces around 160 million tons of rice husk (widely available waste) of which, during the milling process, about $78 \%$ of the weight is rice, broken rice and bran, while the rest, $22 \%$ of the weight of the paddy, is the husk [10]. Malaysia alone produces approximately 3 million tons of rice paddies each year [9]. Table shows the top 10 highest countries that produced rice paddy in 2013 [9]. Asia is still expected to sustain growth in the world rice production in 2013.

The advantage of rice is that it produces a high volume of rice husk, which is a low-density residue of the process [11]. At present, the rice-producing countries are hindered by the landfill problem of the rice husk, which they are attempting to utilize to benefit the economy. When dumped, this waste covers a large area and can self-incinerate, thereby spreading its ash over a wide area and causing significant environmental problems. Unless used, this large quantity of rice husk goes to waste and becomes a major challenge to the environment by destroying the land and the areas surrounding its dumping ground. A huge amount of RHA is produced globally and has been estimated to be growing at more than 7.5 million tons, or, approximately $1.1 \%$ each year [9].

2.1.1.1. Properties of rice husk ash (RHA). Rice husk ash (RHA) is a carbon neutral green product gained from raw rice husk that is changed to ash using the combustion process. The colour of the rice husk ash (RHA) ranges from white grey to black, depending on the source of the raw material, method of incineration, time and burning temperature. Many ways of disposal have been considered including the commercial method of RHA. Rice husk is burnt in a furnace/incinerator with a controlled laboratory atmosphere of $600-800^{\circ} \mathrm{C}$. After the firing process, the produced ash is cooled, either rapidly or slowly. The rapid cooling method is performed by uniformly distributing the ash in trays at a laboratory ambient temperature of $21 \pm 1{ }^{\circ} \mathrm{C}$ after reaching the required temperature of $800{ }^{\circ} \mathrm{C}$. The slow cooling method involves, leaving the ash in the incinerator. It can be used in large amounts to make special supplementary concrete mixes. This RHA, in turn, contains around $85-90 \%$ of amorphous silica [13-15].

Zain et al. [15] reported a new method for producing RHA. The rice husk, as displayed in Fig. 1(a), is the raw form after the milling process, which is fired in a gas furnace at a rate of $10^{\circ} \mathrm{C}$ per minute up to $700{ }^{\circ} \mathrm{C}$, and maintained at this temperature for $6 \mathrm{~h}$. Thereafter, it is left to cool at room temperature, as shown in Fig. 1(b). There are various chemical compositions of rice husk ash due to the type of paddy, differences in the type of land, harvest year, combustion temperature, cooling method and geographical conditions.

RHA is a very fine material. The average particle size of RHA ranges from 5 to $10 \mu \mathrm{m}$ [14]. Table 2 shows the physical and chemical properties of RHA, Portland cement and some cementitious materials. RHA should meet the requirements of the chemical composition of pozzolan to be used in cement and concrete, as stated in ASTM C618. The amount of silicon dioxide $\left(\mathrm{SiO}_{2}\right)$, iron oxide $\left(\mathrm{Fe}_{2} \mathrm{O}_{3}\right)$ and aluminium oxide $\left(\mathrm{Al}_{2} \mathrm{O}_{3}\right)$ in the ash should not be less than $70 \%$, and the loss of ignition (LOI) must be up to $12 \%$, as mentioned in the ASTM requirements. In addition, Chauhan and Kumar [75] clearly explained the importance physical properties of material used that control the flow of micro-system in concrete such as surface area, fineness, incineration system and porosity.

Fig. 3 shows the SEM morphology of the RHA powder. As shown in this figure, RHA grains are in different shapes and have porosity on the surface. Thus causing the mixing water to be absorbed, and reducing the slump value and workability. In addition, Fig. 2 shows that the cellular shape of rice husk ash gets broken due to the longer period of the grinding process. After the grinding process within 15, 60 and $120 \mathrm{~min}$, the average diameter of the rice husk ash particle was $49.0 \mu \mathrm{m}$ (Fig. 2a), $41.0 \mu \mathrm{m}$ (Fig. 2b) and $16.6 \mu \mathrm{m}$ (Fig. 2c), respectively. As described in Fig. 2a, the cellular shape of RHA could be clearly seen. The transformation occurs for $120 \mathrm{~min}$ (Fig. 2c), the cellular particles become smaller and disappear. This observation determines that the RHA sample is composed of irregular shaped particles with micro-pores, which could significantly affect the properties of the final product. Researchers $[8,13-16]$ agree that finer pozzolanic ash is better. The fineness of the RHA is important because it influences the rate of reaction and gains in concrete strength. The fineness also influences the water-cement ratio, workability, shrinkage and creep of 
Table 1

\begin{tabular}{|c|c|c|c|c|c|}
\hline Country & $\begin{array}{l}\text { Rice paddy production in } \\
2013 \text { (Mt) }\end{array}$ & $\begin{array}{l}\text { Husk produced } \\
(20 \% \text { of total) }(\mathrm{Mt})\end{array}$ & $\begin{array}{l}\text { Potential ash production } \\
\text { (18\% of husk) (Mt) }\end{array}$ & $\begin{array}{l}\text { Rice paddy production in } \\
2002(\mathrm{Mt})\end{array}$ & $\begin{array}{l}\text { Incremental (\%) from } \\
2002 \text { to } 2013\end{array}$ \\
\hline China & 200.0 & 40.0 & 7.2 & 177.6 & 11.2 \\
\hline Bangladesh & 45.0 & 9.0 & 1.6 & 39.0 & 13.3 \\
\hline Vietnam & 40.0 & 6.0 & 1.1 & 31.3 & 21.8 \\
\hline West Africa & 13.4 & 2.7 & 0.1 & 10.7 & 20.1 \\
\hline Malaysia & 3.0 & 0.6 & 0.1 & 2.7 & 10.0 \\
\hline Europe & 2.9 & 0.6 & 0.1 & 1.7 & 41.4 \\
\hline Australia & 1.2 & 0.3 & 0.1 & 0.9 & 25.0 \\
\hline Others & 168.5 & 33.7 & 6.1 & 121.9 & 27.7 \\
\hline Total (world) & 741.4 & & & 579.5 & 21.9 \\
\hline Area (ha) in 2013 & 164 million hectares & & & & \\
\hline
\end{tabular}

concrete. Mahmud et al. [17] reported that finer RHA particles yield a larger surface area and increase the strength of the concrete. The very fine and chemically reactive substance would fill the empty columns in the concrete in an optimum manner. Fig. 4 shows photos of the rice husk in raw conditions (4a) that was obtained from a rice mill located in Kuala Selangor, Malaysia. The RHA conditions before and after the grinding process are displayed in Fig. 4b and c, respectively.

2.1.1.2. Rice husk ash as pozzolan. Papadakis and Tsimas [19] confirmed that the sustainable development of the cement and construction industries could be achieved by maximizing of the use of the cementitious and pozzolanic by-products. According to ASTM C 595 [17], a pozzolan is defined as "a siliceous or siliceous and aluminous material, which in itself possesses little or no cementitious value but will, in finely divided form and in the presence of moisture, chemically react with calcium hydroxide to form compounds possessing cementitious properties (pozzolanic activity)". It can be explained that when pozzolanic materials are combined with Portland cement, they will react to form cementitious properties, whereas by themselves, they do not possess any cementitious properties. Therefore, a cementitious material can exhibit a self-cementitious (hydraulic) activity and contains quantities of $\mathrm{CaO}$ while a pozzolanic materials requires $\mathrm{Ca}(\mathrm{OH})_{2}$ to form strength. It is generally accepted that the $\mathrm{CaO}$ content of the last material is sufficient to react with all the pozzolanic compounds and show pozzolanic activity (pozzolanic and cementitious materials). Consequently, all these materials are often used in a mixture with Portland cement which is essential for their activation, $\mathrm{Ca}(\mathrm{OH})_{2}$ from its hydration.

The possible chemical reaction between silica and $\mathrm{Ca}(\mathrm{OH})_{2}$ in the presence of water is as follows:

$n \cdot \mathrm{SiO}_{2}+n \cdot \mathrm{Ca}(\mathrm{OH})_{2}+\mathrm{H}_{2} \mathrm{O} \rightarrow n \cdot \mathrm{Cax} \cdot \mathrm{SiO} \cdot n \cdot \mathrm{H}_{2} \mathrm{O}$

It was found that the secondary $\mathrm{C}-\mathrm{S}-\mathrm{H}$ gel was obtained from a reaction between the silica $\left(\mathrm{SiO}_{2}\right)$ and $\mathrm{Ca}(\mathrm{OH})_{2}$, as stipulated in the chemical equilibrium above (Eq. (1)). According to Sugita et al. [21], the formation of $\mathrm{C}-\mathrm{S}-\mathrm{H}$ gel in RHA-concrete was possibly caused by the reaction between the $\mathrm{SiO}_{2}$ present in the RHA and the $\mathrm{Ca}(\mathrm{OH})_{2}$ in the hydrating cement. They proposed that the $\mathrm{C}-$ $\mathrm{S}-\mathrm{H}$ gel was chemical structure of the $\mathrm{Ca}_{1.5} \mathrm{SiO}_{3.5} \cdot x \mathrm{H}_{2} \mathrm{O}$.

In the combustion process, the matrix of cellulose-lignin from the raw rice husk burns up and remains only as a porous silica skeleton. The RHA is considered as a good super-pozzolan material in the production of concrete due to its high silica content. Thus, the RHA contains a large volume of silica [12,19], and constitutes a highly reactive pozzolanic material. The optimized and highly reactive rice husk ash is found when it is incinerated under a controlled temperature. The optimized RHA properties could be used as a pozzolanic material in concrete. The duration and temperature of the furnace are important parameters that influence the reactivity of the RHA pozzolans. The silica in the rice husk initially exists in an amorphous form. However, it may become crystalline when the rice husk is burnt at high temperature. In addition, the silica in the RHA will not remain porous and amorphous when combusted for a long period at a low temperature $\left(<500^{\circ} \mathrm{C}\right)$, or at a very high temperature for a short time (only a few minutes). In other words, the produced rice husk ash contains up to $90 \%$ amorphous silica, which satisfies the other requirements of the ASTM standard C618-03.

2.1.1.3. Rice husk ash as SCM in concrete. Supplementary cementitious materials (SCMs), often referred to as mineral admixtures, should satisfy the requirements of the established standards for use in concrete. The utilization of any SCMs will increase its output, such as the hydraulic factors, permeability, strength, unit weight, durability and volumetric constancy over a long period. The RHA is the product of a supplementary cementitious material (SCM) from the agro-industry. As early as 1942, Pitt [23], explored the use of RHA as a supplementary cementitious material for producing high strength concrete [20]. Most studies have indicated that the standard compressive strength of concrete combined with or without cementitious materials (SCMs), is within the range for conventional concrete (15-45 Mpa) and has a density of about $2400 \mathrm{~kg} / \mathrm{m}^{3}$ [8,21-23]. However, recent studies have shown the possibility of producing high strength concrete up to $55 \mathrm{MPa}$ and 72 MPa for 7 and 28 days curing [24], respectively. Promoting the compressive strength of concrete and the ability to produce high strength concrete with SCMs, such as RHA, is very important because the compressive strength of concrete plays a fundamental role in the design and construction of concrete structures [25]. The methods and procedures for producing high strength RHA concrete have been examined in various published papers [8,12-14]. Table 3 shows some selected mix proportions of concrete containing RHA in several combinations of designs. In general, the RHA concrete had higher compressive strengths at various ages and up to 90 days when compared with the normal concrete without RHA and or SCMs. Improvements in the mechanical and durability properties of the concretes containing RHA can be explained by the chemical and physical effects of RHA. RHA reduces the number of the large 


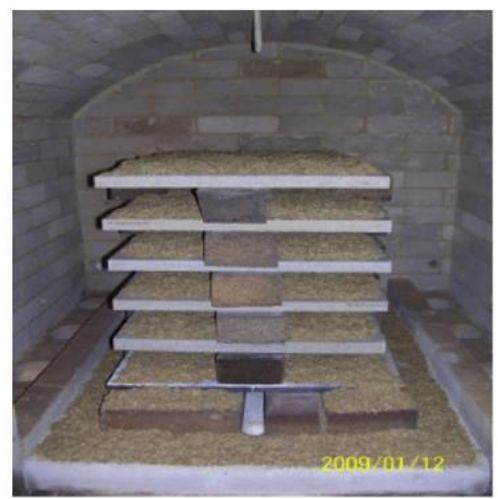

(a)

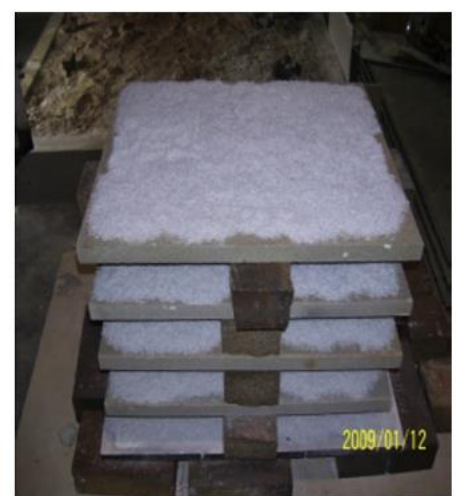

(b)

Fig. 1. (a) Raw rice husk and (b) rice husk ash (RHA) [15].

Table 2

The chemical and physical properties of Portland cement and some cementitious materials $[5,8,11,18,27,34,35,69,74,75]$.

\begin{tabular}{|c|c|c|c|c|c|}
\hline Chemical composition (\%) & Ordinary Portland cement I & Ordinary Portland cement II & Rice husk ash (RHA) & Palm oil fuel ash (POFA) & Corn cob ash (CCA) \\
\hline $\mathrm{SiO}_{2}$ & $20.4-22.0$ & 21.9 & $80.7-95.9$ & $59.6-66.9$ & $65.4-67.3$ \\
\hline $\mathrm{Fe}_{2} \mathrm{O}_{3}$ & $2.3-4.2$ & 3.3 & $0.2-2.9$ & $1.9-5.7$ & $3.8-5.6$ \\
\hline $\mathrm{CaO}$ & $61.5-65.4$ & 62.3 & $1.1-1.5$ & $4.9-6.4$ & $10.3-12.9$ \\
\hline $\mathrm{SO}_{3}$ & $2.2-3.0$ & 2.1 & $0.7-1.2$ & $0.3-1.3$ & $1.0-1.1$ \\
\hline $\mathrm{Na}_{2} \mathrm{O}$ & $0.1-0.2$ & 1.2 & $0.9-1.2$ & $0.2-0.8$ & $0.4-0.5$ \\
\hline $\mathrm{K}_{2} \mathrm{O}$ & $0.3-1.1$ & 0.3 & $0.8-2.1$ & $5.0-7.5$ & $4.2-5.7$ \\
\hline LOI & $0.4-2.3$ & 1.1 & $2.8-6.6$ & $6.6-10.0$ & $0.9-1.5$ \\
\hline Median particle size $(\mu \mathrm{m})$ & - & - & $5.0-10.0$ & 10.5 & $29.0-45.0$ \\
\hline Specific gravity & $3.0-3.3$ & $2.90-3.2$ & $2.0-2.2$ & $1.9-2.4$ & $2.5-3.6$ \\
\hline Blaine fineness $\left(\mathrm{m}^{2} / \mathrm{kg}\right)$ & $336.5-399.0$ & 305.0 & $350.0-376.8$ & 493.0 & $270.0-385.0$ \\
\hline
\end{tabular}

pores and increases the probability of transforming the continuous pores into discontinuous ones. Hence, all these mechanisms make the microstructure of the paste more homogeneous and dense. The performance of concrete with RHA as a supplementary cementitious material (partially cement replacement) is outstanding considering its resistance to water $[8,10]$ and chloride ion penetration [24], which, in many cases, constitute the most important characteristic for durability and the prevention of corrosion. The highlighted properties that are the result of air permeability and chloride ion penetration will show different behaviors depending on the $w / c$ ratio used in the mixtures. Moreover, the incorporation of RHA in concrete materials resolves the current problems associated with the disposal of RHA.

2.1.2. Palm oil fuel ash (POFA)

2.1.2.1. Origins of palm oil fuel ash (POFA). The oil palm is a tropica palm tree, which is easily cultivated in tropical countries, such as Malaysia, Indonesia, Thailand, Africa, and Latin America, 90\% of the palm oil production is generated by three of the ASEAN countries. Palm oil can be grown in many parts of the tropical world, but is mainly productive within the equator line, which include Indonesia, Malaysia, and several parts of Thailand. The high productivity of oil palm is concentrated in the tropical zone; located $10^{\circ}$ to the North or South of the equator. Fig. 5 shows the worldwide production of palm oil in 2009 [10]. Malaysia produces 7 million tons of crude palm oil each year [26], and Thailand produces 100,000 tons of palm oil fuel ash (POFA)annually [31], which is likely to increase due to the development of palm tree plantations.

Palm trees are generally used in commercial agriculture. They do not produce branches and are spread by sowing the seeds. It comprises an oily, fleshy outer layer, with a single seed (kernel), which is rich in oil [29]. Tangchirapat et al. [30] defined POFA as an agro-waste ash from which palm oil residue, such as palm fibre and shells, is burnt at temperatures of $800-1000{ }^{\circ} \mathrm{C}$ to produce steam for the generation of electricity in biomass thermal power plants. The typical oil palm residue constitutes $15 \%$ shell and $85 \%$ fibre. To produce energy, the empty fruit bunches are burned in a boiler. Generally, it also produces about $5 \%$ ash by weight of solid waste. The solid waste and ash material produced are rarely used, thus, posing a serious ecological problem through the concomitant pollution of the environment. Thus, it should present a feasible solution to both the problem of land-filling as well as the high cost of building materials and pollution of the planet. Basically, waste disposal is always considered as a "negative value" due to the costly practices. In addition, the manageable maximized use of POFA will produce "positive value" products as well reduce the environmental problems. Compared to other types of palm-oil by-product, both the 20th and 21st century, POFA has represented an environmental disruption pollutant that ends-up in the atmosphere without being utilized.

2.1.2.2. Manufacture and properties of POFA. Palm oil fuel ash (POFA) is a waste product obtained in the form of ash through

Link to Full-Text Articles:

http://www.sciencedirect.com/science/article/pii/S0950061814011507 